\title{
Investigation of Milling Stability under Cutting Fluid Supply by Microphone Signal Analysis
}

\author{
Rong-Mao Lee, ${ }^{1 *}$ Pao-Ting Liu, ${ }^{2}$ and Cheng-Chi Wang ${ }^{3}$ \\ ${ }^{1}$ Computer and Intelligent Robot Program for Bachelor Degree, National Pingtung University, \\ No. 4-18, Minsheng Rd., Pingtung City, Pingtung County 90003, Taiwan \\ ${ }^{2}$ Department of Mechanical Engineering, National Chin-Yi University of Technology, \\ No. 57, Sec. 2, Zhongshan Rd., Taiping Dist., Taichung City 41170, Taiwan \\ ${ }^{3} \mathrm{Ph}$.D. Program, Graduate Institute of Precision Manufacturing, \\ National Chin-Yi University of Technology, \\ No. 57, Sec. 2, Zhongshan Rd., Taiping Dist., Taichung City 41170, Taiwan
}

(Received January 18, 2018; accepted July 17, 2018)

Keywords: milling vibration, milling noise, scatter diagram of time domain, stability lobe diagram

Force and acceleration are the most well-known signals for the monitoring of milling vibration. However, the noncontact and low-cost microphone is also a potential choice for cutting vibration measurement. The superior detection sensitivity of the microphone against milling dynamics was preliminarily verified. However, the limitations of microphones to record milling vibration have also been reported over the past two decades, such as the vibration identification accuracy under the influence of environmental noise. In this work, the microphone signal beyond $5 \mathrm{kHz}$ is employed in the milling stability analysis to diminish the effect of low-frequency environmental noise. In addition, almost all current studies for cutting noise analyses are conducted without cutting fluid (dry cutting). This is far from most practical manufacturing processes. The cutting fluid is used in this work and a waterproof device is particularly designed to ensure the microphone operation against the cutting fluid. The microphone signal is analyzed on the basis of the scatter diagram of time domain (SDTD) to discuss the variation trend due to the milling stability. In addition, both the fast Fourier transform (FFT) and short-time Fourier transform (STFT) were employed to clarify the signal characteristics in the frequency domain. Finally, the finished workpiece surface was examined with the stability lobe diagram (SLD) to verify the acoustic analysis results.

\section{Introduction}

Force, vibration, and acoustic signals are the main signals for chatter detection analyses. ${ }^{(1)}$ Dynamometers and accelerometers have been frequently employed to record the variations in cutting force and vibration, respectively, during milling. Tlusty and Andrew applied three kinds of sensors to turning and milling processes to observe the sensor detection sensitivity against chatter. ${ }^{(2)}$ Studies regarding the development of tool condition monitoring (TCM) have

*Corresponding author: e-mail: maxmou@mail.nptu.edu.tw https://doi.org/10.18494/SAM.2018.1978 
been reported by Chen and Hen ${ }^{(3)}$ and Dimla and Lister. ${ }^{(4)}$ Signals of the dynamometer and accelerometer have been utilized to verify the cutter condition. A predictive model of milling stability based on the accelerometer signal was proposed by Clancy et al. ${ }^{(5)}$ The occurrence of chatter can be determined by the strong vibration frequencies close to the machine tool natural frequencies. The turning chatter detection according to cutting force signals was introduced by Zhang et al. ${ }^{(6)}$ The cutting force signals are classified into three categories (stable, transient, and chatter) with the aid of wavelet packet decomposition (WPD) and support vector machine (SVM).

Two kinds of acoustic sensors can be employed in the detection of milling dynamics. Microphones are noncontact sensors that are usually utilized to record audible sound signals $(20-20 \mathrm{kHz})$. On the other hand, the acoustic emission (AE) sensor can be used to monitor the vibration signal inside a solid structure (beyond $20 \mathrm{kHz}$ ). The AE sensor has already been applied to detect cutter sharpness, and the efficacy of tool wear detection has been preliminarily confirmed as well. ${ }^{(7-10)}$ The source of the AE signals was defined by Li in 2002. ${ }^{(11)}$ The AE signals are composed of continuous and transient signals. Continuous signals are related to shearing in the primary zone and wear on the tool face and flank, whereas transient signals are associated with tool fracture or chip breakage. Besides the tool wear detection, AE signals have also been applied to the performance verification of the multidimensional chatter stability model ${ }^{(12)}$ the regulation of partial machining parameters, ${ }^{(13)}$ and the determination of chip type. ${ }^{(14,15)}$ According to the investigation of the relationship between the AE signals and the chip style, the source of the AE signals is mainly from the tool wear, the plastic deformation of the workpiece, and the chip conformation. ${ }^{(15)}$ Since the AE signal is usually in the very high frequency range $(\gg 20 \mathrm{kHz})$, the efficacy of chatter detection by AE sensors is still indefinite owing to the signal strength decay in the high frequency range.

For the application of a microphone in metal cutting monitoring, environmental noise is always a concern. However, some works regarding the sound analysis of the cutting process have been reported. A condition identification technique for the manufacturing process was proposed by Takata et al. ${ }^{(16)}$ This method is also called "speech recognition" and it has already been deployed to commercial vertical machining centers. In consideration of the sensor cost, the microphone was utilized to monitor vibration by Riviere et al. ${ }^{(17)}$ Three analysis steps for the microphone signal against chatter detection were suggested:(17) (i) define a threshold for the signal strength, (ii) observe the signal variation in the frequency domain, and (iii) calculate the cutter displacement by observing the sound pressure, as illustrated in Ref. 18. Two works regarding the microphone application in the milling process were finished in $2009^{(19)}$ and 2010. ${ }^{(20)}$ The effects of processing parameters on milling sound frequencies were studied. A similar study was accomplished by Cao et al. ${ }^{(21)}$ Four kinds of time-frequency domain analysis methods were involved in the milling sound analysis, including short-time Fourier transform (STFT), continuous wavelet transform (CWT), Wigner-Ville distribution (WVD), and synchrosqueezing transform (SST). An acoustic chatter signal index (ACSI) and the spindle-speed compensation strategy (SSCS) were proposed by Tsai et al. ${ }^{(22)}$ to quantify the microphone signal and regulate the spindle speed. The performance of the real-time chatter prevention strategy based on acoustic signal feedback was determined and verified. 
The potential of a microphone to be applied to chatter detection was preliminarily confirmed. ${ }^{(23,24)}$ The purpose of this work is to investigate the milling stability by sound analyses, especially the milling dynamics under cutting fluid supply. A waterproof device for the microphone has been specially designed to overcome the limit of moist environment application. The stability lobe diagram (SLD) was employed in the experimental design. The finished workpiece surface and microphone signals were both used in the study of the efficacy of chatter detection by acoustic signal analyses.

\section{Materials and Methods}

The research process is shown in Fig. 1. Both the microphone and accelerometer were employed in the practical milling tests. The accelerometer signal plays the role of signal comparison baseline. Three test modes of microphone signals were defined as follows:

* no cutting fluid supply (dry cutting) and no waterproof device equipped

* no cutting fluid supply (dry cutting) and waterproof device equipped

* cutting fluid supplied (wet cutting) and waterproof device equipped

The scatter diagram of time domain (SDTD) and fast Fourier transform (FFT) were employed to clarify the validity of the milling parameters against microphone signal acquisition. Three stages were included in this step as follows:

* confirmation of the appropriate spindle speed range for practical milling tests,

* observation of the signal distinctions among three microphone test modes, and

* determination of the main signal frequency range of microphone signals.

The SDTD was also utilized to confirm the microphone performance inside the waterproof device.

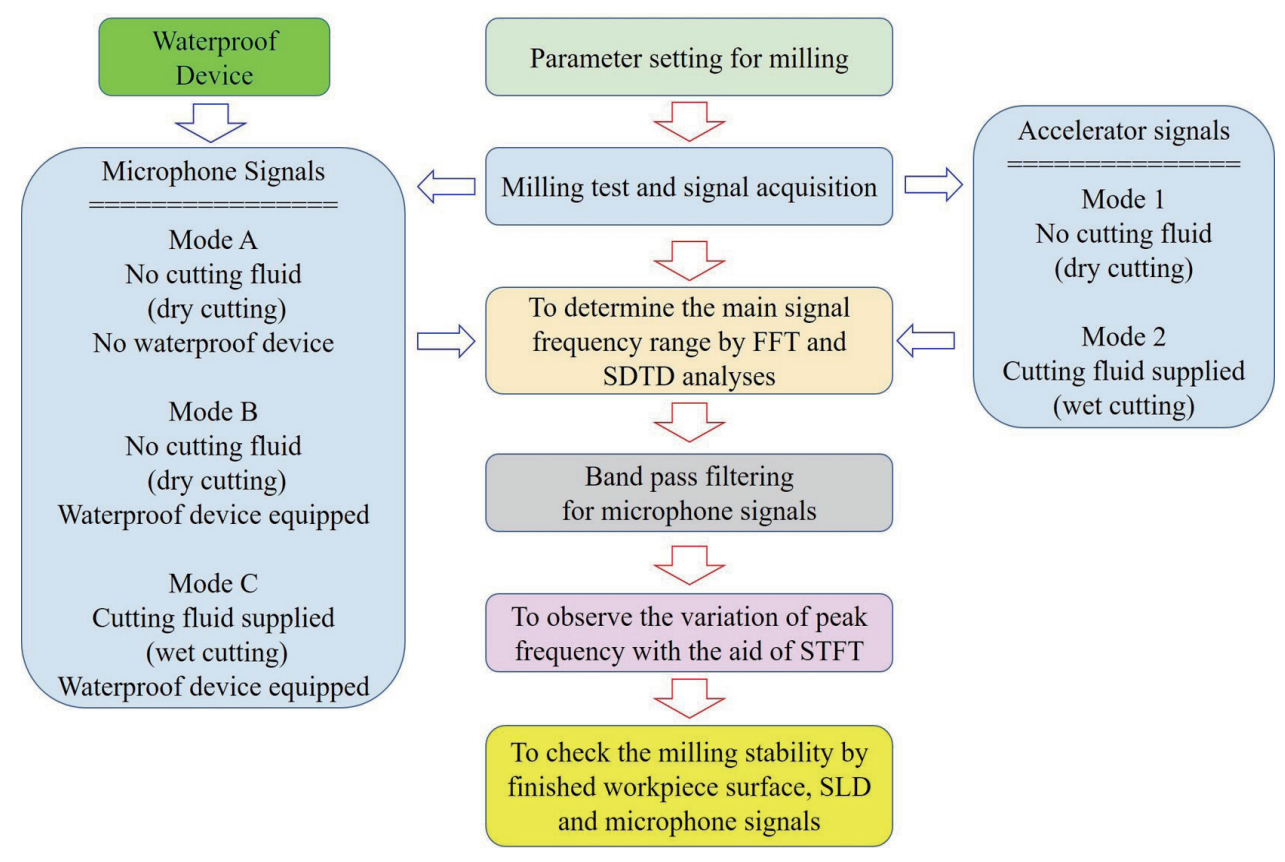

Fig. 1. (Color online) Research procedure. 


\section{$2.1 \quad$ SDTD}

Marinescu and Axinte ${ }^{(25)}$ applied SDTD to observe the cutting stability. The $x$ - and $y$-axes of SDTD are the signal-to-noise ratio (S/N ratio) of the spindle motor current and the root mean square (RMS) of AE signals, respectively. The trends toward the unstable state of three cutting modes (roughing/semifinishing/finishing) are much different. A similar study was reported by Uekita and Takaya, ${ }^{(26)}$ but the signals for the $x$ - and $y$-axes are the AE signal and cutting force, respectively. In this work, SDTD was employed to observe the sound strength variation due to the variation in milling dynamics. For example, Fig. 2 shows the SDTD comparison for three different spindle speeds (feed rate: $800 \mathrm{~mm} / \mathrm{min}$, axial cut depth: $1 \mathrm{~mm}$, no waterproof device and cutting fluid are applied). The $x$ - and $y$-axes of the individual milling test are the signals of the accelerometer and microphone, respectively. The dotted lines in Fig. 2 refer to the peak sound strength without cutting, but the spindle is rotating. On the basis of the results, the effect of environmental noise can be reduced while the spindle speed is beyond $6000 \mathrm{rpm}$.

\subsection{Design and verification of microphone waterproof device}

The proposed microphone waterproof device is shown in Fig. 3. It is mainly composed of six components. Component A2 is only for device waterproof tests. Component A1 is utilized to protect the microphone cable against the cutting fluid. Component B is an O-ring. Component $\mathrm{C}$ is the housing for the microphone. The microphone (component $\mathrm{D}$ ) can be fixed inside component $\mathrm{C}$ by waterproof screws. Component $\mathrm{E}$ is a membrane made of polyfluorotetraethylene (PTFE). The PTFE material is capable of maintaining an acceptable sound transmittance and waterproof performance simultaneously. Component $\mathrm{F}$ is a cap for the fixation of the PTFE membrane. A two-step test procedure was designed for the proposed device before it is practically employed in the milling tests. The first step is to check the

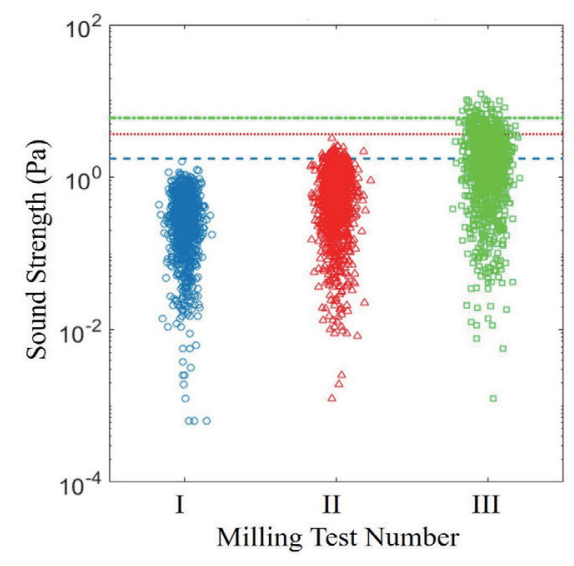

Fig. 2. (Color online) Comparison of SDTD for various spindle speeds: (I) 2000, (II) 4000, and (III) $6000 \mathrm{rpm}$.

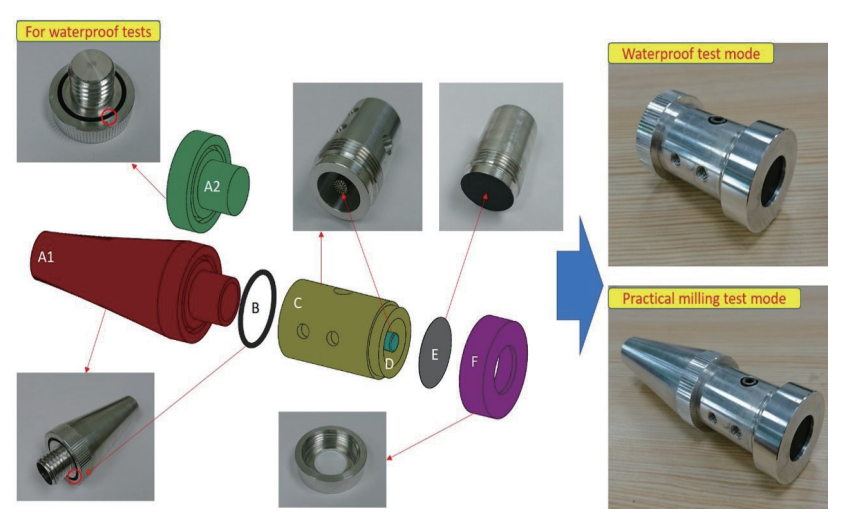

Fig. 3. (Color online) Components of the proposed waterproof device. 
waterproof performance of the device. The second step is to investigate the effect of the waterproof device on the microphone signal. The waterproof test is designed according to the ISO-20653 standard. The required waterproof grade is IPX7, which means that the device can ensure waterproof efficacy under $1 \mathrm{~m}$ of water for a short time. The test rig is shown in Fig. 4(a). Litmus papers were employed to verify the device waterproof efficacy and they were placed behind the position of the PTFE membrane. The test results are shown in Figs. 4(b) and 4(c). There is no water observed inside component $\mathrm{C}$, regardless of 10 or $30 \mathrm{~min}$ of testing. In other words, the proposed waterproof device meets the ISO-20653 requirements.

After the waterproof test, the effect of the PTFE membrane on microphone signal properties was investigated. The test rig is shown in Fig. 5. The distance between the speaker and the microphone is set to be $85 \mathrm{~mm}^{(19)}$ and the volume of the reference signal is fixed. The frequency of the reference signal is from $1 \mathrm{k}$ to $10 \mathrm{kHz}$ and the frequency interval is $1 \mathrm{kHz}$. The

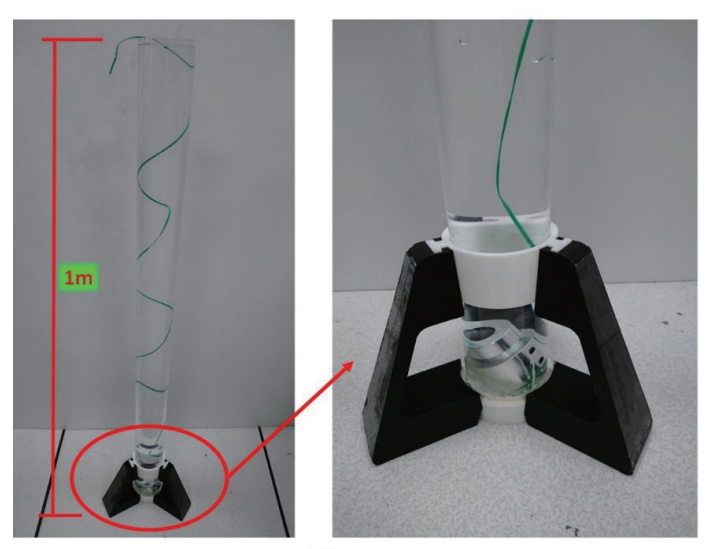

(a)

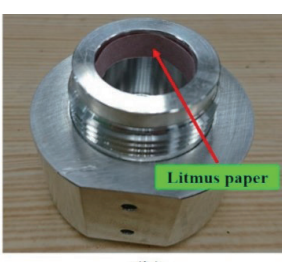

(b)

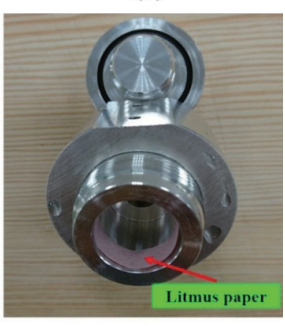

(c)

Fig. 4. (Color online) Test rig for waterproof tests: (a) $1 \mathrm{~m}$ water depth based on ISO-20653 rules, (b) 10 min test result, and (c) 30 min test result.

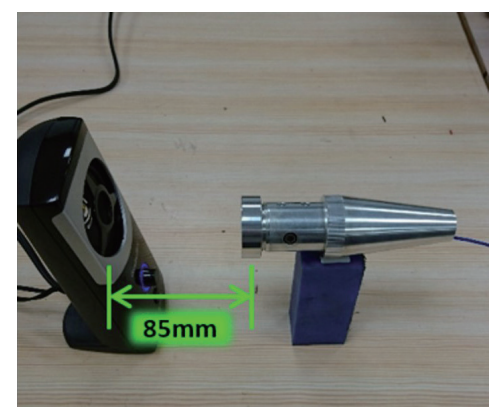

(a)

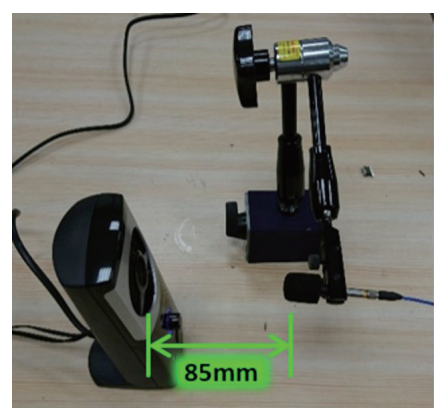

(b)

Fig. 5. (Color online) Positions of speaker and microphone: (b) with and (a) without waterproof device. 
comparison of sound strengths versus various sound frequencies with and without a waterproof device is shown in Fig. 6 . The $x$ - and $y$-axes in Fig. 6 refer to the reference signal frequency and maximum sound strength by the microphone, respectively. For frequencies below $6 \mathrm{kHz}$, a significant decay of sound strength due to the PTFE membrane was observed. However, the sound strength decay due to the PTFE membrane can be ignored beyond the signal frequency of $6 \mathrm{kHz}$ owing to the increase in sound transmittance. Since the sound strength below $6 \mathrm{kHz}$ is still detectable, the effect of the PTFE membrane on the microphone signal should be acceptable.

\subsection{Experimental design}

The test rig is shown in Fig. 7 and the employed hardware is listed in Table 1. The distance between the microphone and the workpiece is $85 \mathrm{~mm},{ }^{(19)}$ and the full slot milling was applied. The SLD for the milling setup is shown in Fig. 8 and 45 milling tests in total were conducted (see Table 2).

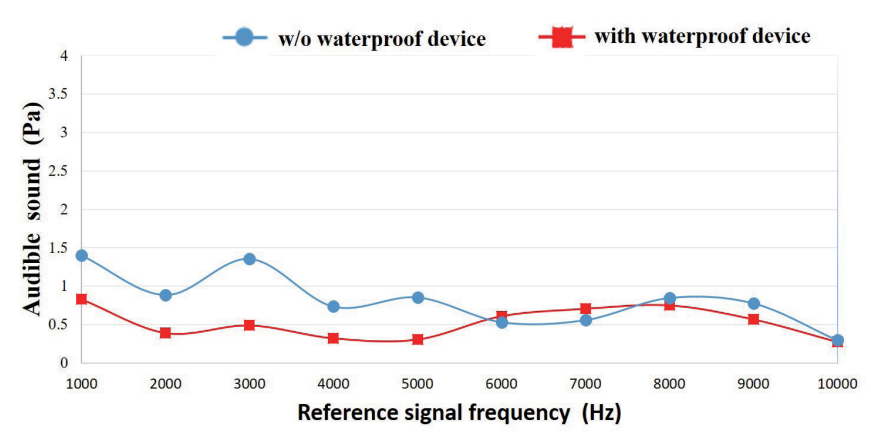

Fig. 6. (Color online) Sound tests for PTFE membrane.

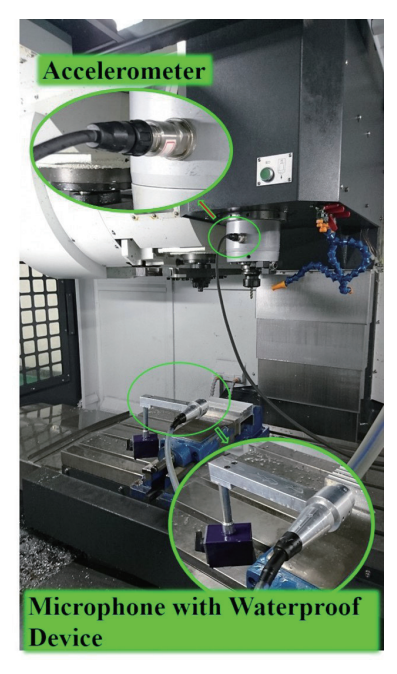

Fig. 7. (Color online) Test rig.

Table 1

Experimental hardware specifications.

\begin{tabular}{lcc}
\hline Item & Brand/Model/Material & Remarks \\
\hline Microphone & PCB/378C01 & Bandwidth: $20-80 \mathrm{kHz}$ \\
Accelerometer & PCB/601A01 & Bandwidth: $0.27-10 \mathrm{kHz}$ \\
Notebook & HP/ProBook 430 G1 & For signal recording \\
Data acquisition module & NI/ USB-4431 & 4-port and USB interface \\
CNC machine tool & FEELER/VMP-40A & Experimental machine \\
& & Material: cobalt high-speed steel \\
Cutter & WEENIX/End mill & Number of teeth: 3 \\
& & Diameter: $8 \mathrm{~mm}$ \\
Workpiece & Aluminum 6061 & Size: $150 \times 100 \times 50 \mathrm{~mm}^{3}$ \\
\hline
\end{tabular}




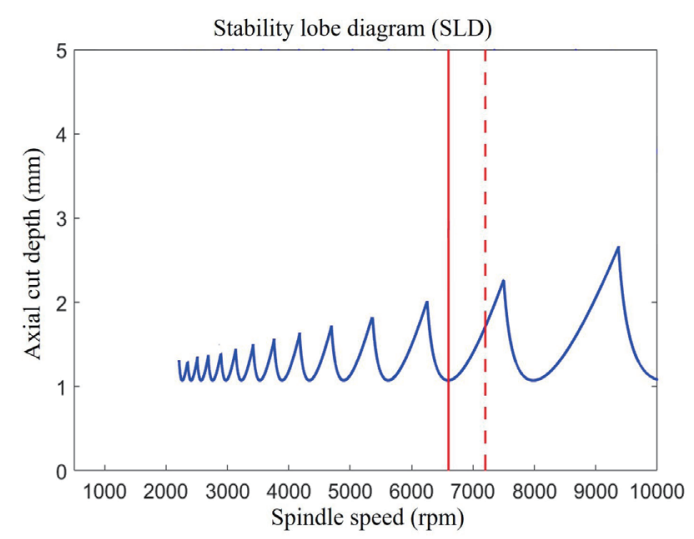

Fig. 8. (Color online) SLD for the experimental setup.

Table 2

Milling tests parameters.

\begin{tabular}{lcccccc}
\hline Group & No. & $\begin{array}{c}\text { Spindle speed } \\
(\mathrm{rpm})\end{array}$ & $\begin{array}{c}\text { Feed rate } \\
(\mathrm{mm} / \mathrm{min})\end{array}$ & Axial cut depth $(\mathrm{mm})$ & $\begin{array}{c}\text { Waterproof } \\
\text { device }\end{array}$ & $\begin{array}{c}\text { Cutting } \\
\text { fluid }\end{array}$ \\
\hline A & $1-9$ & 6600 & 800 & $0.1-0.5 / 1 / 1.5 / 2 / 2.5$ & No & No \\
B & $10-18$ & 6600 & 800 & $0.1-0.5 / 1 / 1.5 / 2 / 2.5$ & Yes & No \\
C & $19-27$ & 6600 & 800 & $0.1-0.5 / 1 / 1.5 / 2 / 2.5$ & Yes & Yes \\
D & $28-33$ & 7200 & 800 & $0.2 / 0.5 / 1 / 1.5 / 2 / 2.5$ & No & No \\
E & $34-39$ & 7200 & 800 & $0.2 / 0.5 / 1 / 1.5 / 2 / 2.5$ & Yes & No \\
F & $40-45$ & 7200 & 800 & $0.2 / 0.5 / 1 / 1.5 / 2 / 2.5$ & Yes & Yes \\
\hline
\end{tabular}

\section{Results}

SDTD comparisons of partial experimental results are shown in Fig. 9. Figure 9(a) shows the effect of the waterproof device on the microphone sound strength. The variations in microphone signal strength due to the cutting fluid are shown in Fig. 9(b). The sound strength variation caused by the cutting fluid is more significant than that by the waterproof device.

The STFTs of Nos. 17 and 26 are shown in Fig. 10. The milling parameters for both of these two tests are $6600 \mathrm{rpm} / 2 \mathrm{~mm}$ axial cut depth/with waterproof device; the only difference between these two tests is the cutting fluid supply. According to the STFT results, the milling dynamics can be observed using the microphone signals at the frequency interval of 5-10 kHz. Figure 11 shows the peak frequency variation of the milling dynamics at the frequency interval of $5-10 \mathrm{kHz}$. The partial finished workpiece surface is shown in Fig. 12. The milling stability from the results of the workpiece surface examination is then put into the SLD, as illustrated in Fig. 13. The milling stability can be detected using the peak frequency variation of microphone signals. Similar test results under $7200 \mathrm{rpm}$ are shown in Figs. 14 and 15. 


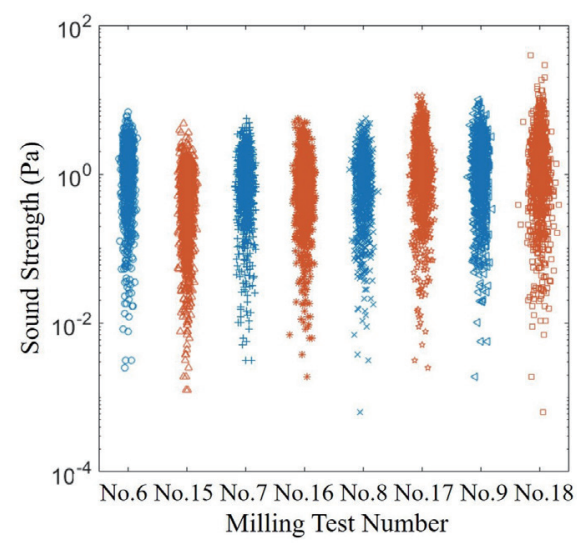

(a)

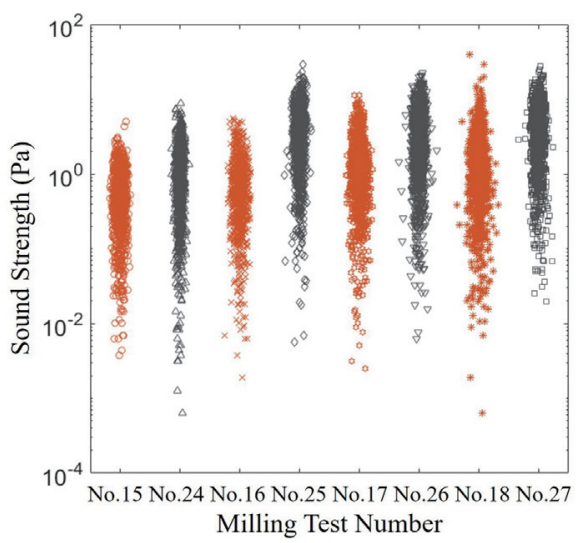

(b)

Fig. 9. (Color online) SDTD comparison for the effects of (a) waterproof device and (b) cutting fluid on microphone signal strength.
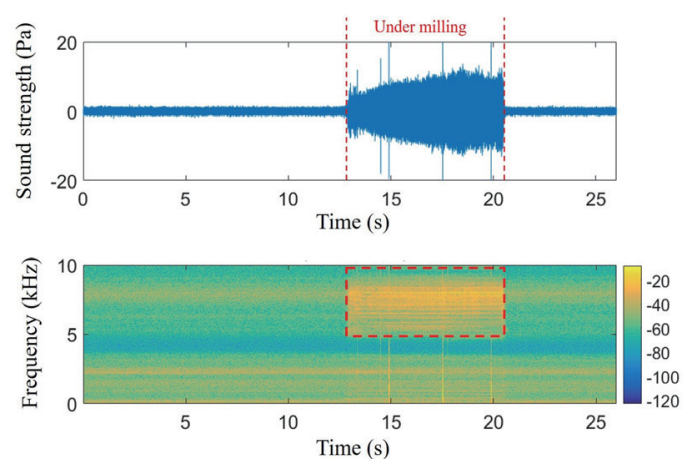

(a)
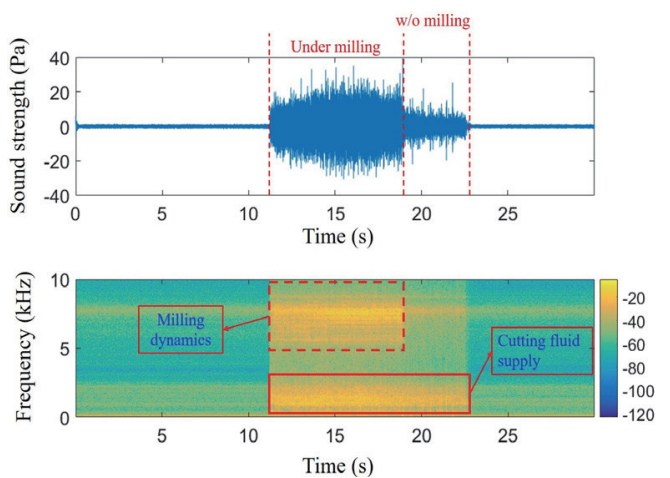

(b)

Fig. 10. (Color online) STFT of test: (a) No. 17 and (b) No. 26.

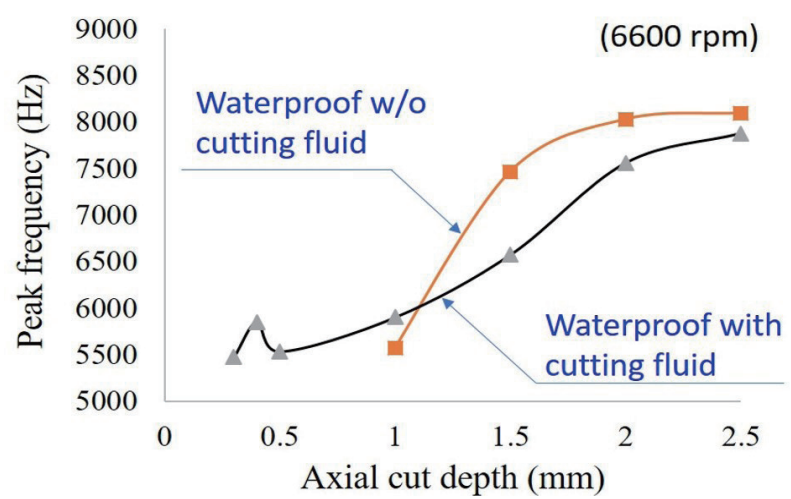

Fig. 11. (Color online) Microphone signal frequency against axial cut depth (6600 rpm). 

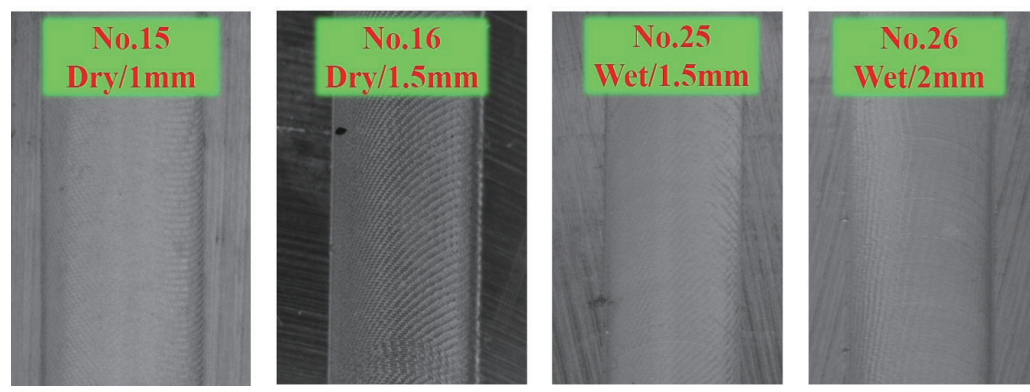

Fig. 12. (Color online) Partially finished workpiece surfaces.

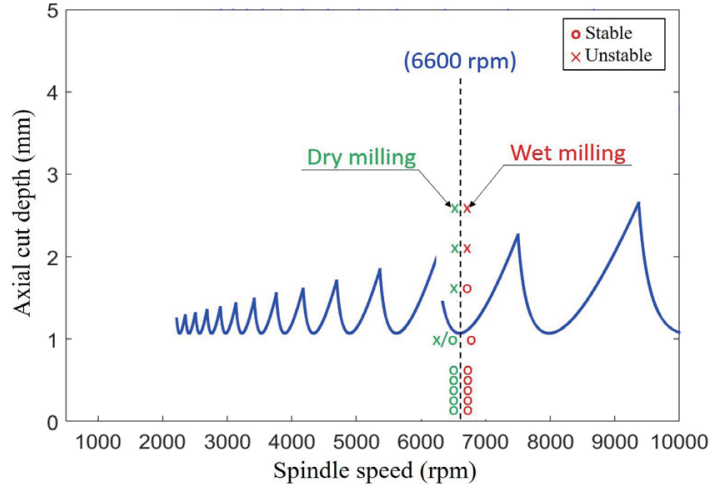

Fig. 13. (Color online) Comparison of milling stability between SLD and milling test results.

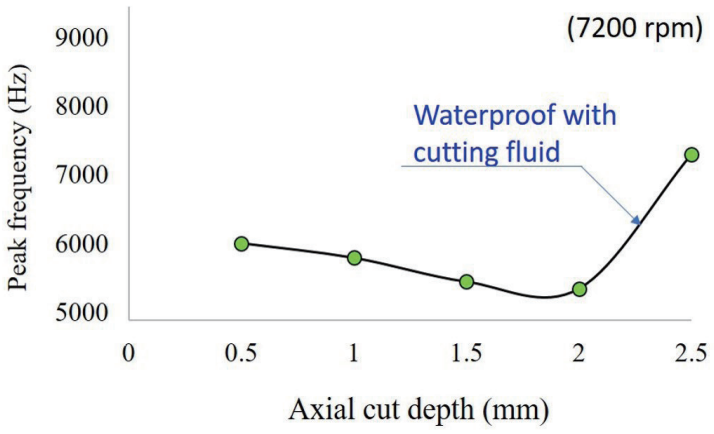

Fig. 14. (Color online) Microphone signal frequency against axial cut depth (7200 rpm).

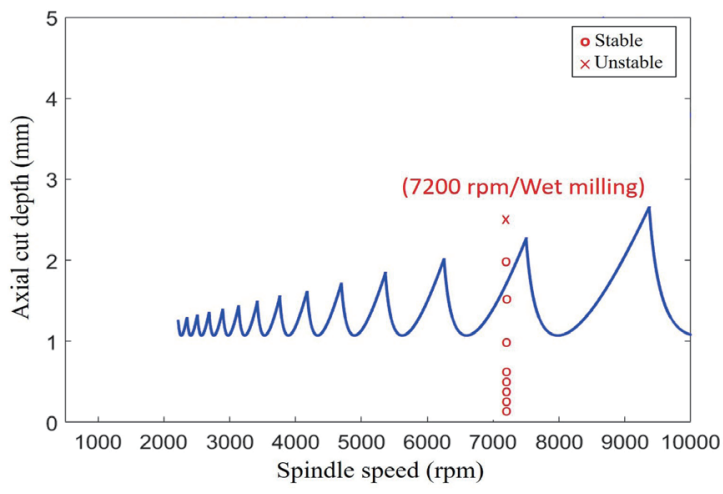

Fig. 15. (Color online) Comparison of milling stability between SLD and milling test results.

\section{Conclusions}

The goal of this work is to propose an analysis method to identify the cutting vibration of wet millings. A waterproof device for a microphone was proposed and the device performance was verified. According to practical milling tests, some conclusions can be made as follows. 
1. Studies regarding the cutting sound analysis are mainly based on dry milling at present. This is far from the practical manufacturing situation. A waterproof device was designed in this work for the application of a microphone in the wet milling process.

2. Although a decrease in sound strength was observed owing to the waterproof device, the microphone performance beyond $6 \mathrm{kHz}$ was no longer affected by the waterproof function.

3. The main frequencies of the cutting fluid supply are below $3 \mathrm{kHz}$. The main frequencies of milling dynamics are below $4 \mathrm{kHz}$ according to the accelerometer signals. However, the frequency variation corresponding to milling dynamics between 5 and $10 \mathrm{kHz}$ was observed using the microphone. Since most of the frequencies of environmental noise are below 5 $\mathrm{kHz}$, the microphone signal analysis versus milling vibration identification can still work very well.

4. The stability variation of milling dynamics can be successfully observed using the peak frequency variation of the microphone signals. From the experimental results, the SLD stability boundary fits the dry milling results. In other words, for most manufacturing situations (wet milling), the axial cut depth can be increased significantly.

\section{References}

1 M. Siddhpura and R. Paurobally: Int. J. Mach. Tools Manuf. 61 (2012) 27.

2 J. Tlusty and G. C. Andrews: CIRP Ann.-Manuf. Technol. 32 (1983) 563.

3 S. L. Chen and Y. W. Hen: Int. J. Mach. Tools Manuf. 40 (2000) 381.

4 D. E. Dimla Sr. and P. M. Lister: Int. J. Mach. Tools Manuf. 40 (2000) 739.

5 B. E. Clancy, B. Rao, and Y. C. Shin: Time Domain Chatter Prediction Including Tool Wear Effects During Face Turning of Nickel Based Super Alloys (Society of Manufacturing Engineers, West Lafayette, 2002) p. 1.

6 Z. Zhang, H. Li, G. Meng, X. T. Tu, and C. M. Cheng: Int. J. Mach. Tools Manuf. 108 (2016) 106.

7 I. Grabec and P. Leskovar: Ultrasonics 15 (1977) 17.

8 S. Y. Liang and D. A. Dorfeld: J. Eng. Ind. 111 (1989) 199.

9 R. Y. Chiou and S. Y. Liang: Int. J. Mach. Tools Manuf. 40 (2000) 927.

10 I. Marinescu and D. Axinte: Int. J. Mach. Tools Manuf. 49 (2009) 53.

11 X. L. Li: Int. J. Mach. Tools Manuf. 42 (2002) 157.

12 E. Budak and E. Ozlu: CIRP Ann.-Manuf. Technol. 56 (2007) 401.

13 I. Marinescu and D. Axinte: Int. J. Mach. Tools Manuf. 51 (2011) 349.

14 A. J. Mian, N. Driver, and P. T. Mativenga: Proc. Inst. Mech. Eng. B J. Eng. Manuf. 225 (2011) 1535.

15 M. S. H. Bhuiyann, I. A. Choudhury, and Y. Nukman: Int. J. Mach. Tools Manuf. 58 (2012) 19.

16 S. Takata, J.H. Ahn, M. Miki, Y. Miyao, and T. Sata: CIRP Ann.-Manuf. Technol. 35 (1986) 289.

17 E. Riviere, V. Stalon, O. V. D. Abeele, E. Filippi, and P. Dehombreux: Proc. 7th National Cong. Theoretical Applied Mechanics (University of Mons, 2006) 1-8.

18 T. L. Schmitz, K. Medicus, and B. Dutterer: Mach. Sci. Technol. 6 (2002) 207.

19 E. M. Rubio and R. Teti: J. Intell. Manuf. 20 (2009) 43.

20 T. Aized: Future Manufacturing Systems (Sciyo, Rijeka, 2010) p. 217.

21 H. R. Cao, Y. T. Yue, X. F. Chen, and X. W. Zhang: Int. J. Adv. Manuf. Technol. 89 (2016) 2747.

22 N. C. Tsai, D. C. Chen, and R. M. Lee: Int. J. Adv. Manuf. Technol. 47 (2011) 1013.

23 W. L. Weingaertner, R. B. Schroeter, M. L. Polli, and J. de O. Gomes: J. Mater. Process. Technol. 179 (2006) 133.

24 T. Thaler, P. Potocnik, I. Bric, and E. Govekar: Appl. Acoust. 77 (2014) 114.

25 I. Marinescu and D. A. Axinte: Int. J. Mach. Tools Manuf. 48 (2008) 1148.

26 M. Uekita and Y. Takaya: Int. J. Adv. Manuf. Technol. 89 (2016) 65. 